\title{
Inhibition of YAP reverses primary resistance to EGFR inhibitors in colorectal cancer cells
}

\author{
BI-SHENG LIU ${ }^{1,2^{*}}$, HONG-WEI XIA ${ }^{2 *}$, SHENG ZHOU $^{1,2}$, QING LIU $^{1,2}$, QIU-LIN TANG ${ }^{2}$, \\ NA-XI BI ${ }^{2}$, JI-TAO ZHOU ${ }^{1}$, QI-YONG GONG ${ }^{3}$, YONG-ZHAN NIE ${ }^{4}$ and FENG BI ${ }^{1,2}$ \\ ${ }^{1}$ Department of Medical Oncology, West China Hospital; ${ }^{2}$ Laboratory of Molecular Targeted Therapy in Oncology, \\ State Key Laboratory of Biotherapy; ${ }^{3}$ Department of Radiology, West China Hospital, Sichuan University, Chengdu, \\ Sichuan 610041; ${ }^{4}$ State Key Laboratory of Cancer Biology and Xijing Hospital of Digestive Diseases, \\ Fourth Military Medical University, Xi'an, Shaanxi 710032, P.R. China
}

Received February 9, 2018; Accepted July 19, 2018

DOI: 10.3892/or.2018.6630

\begin{abstract}
Mutant KRAS and BRAF are associated with primary EGFR inhibitor resistance in colorectal cancer (CRC). However, other biomarkers that could predict EGFR inhibitor resistance remain elusive. In the present study, immunoblotting and cell proliferation results revealed that yes-associated protein (YAP), a downstream effector of the Hippo pathway, was positively associated with primary cetuximab resistance in CRC cells. YAP knockdown enhanced the cytotoxicity of cetuximab in CRC cells. Simvastatin, a 3-hydroxy-3-methylglutaryl-coenzyme A (HMG-CoA) reductase inhibitor of the mevalonate pathway that inhibits YAP bioactivity through nuclear translocation and total YAP expression, increased the cytotoxicity of EGFR inhibitors (cetuximab and gefitinib) against CRC cells. The combination of simvastatin and EGFR inhibitors inhibited YAP and EGFR signaling more markedly than each agent alone. Adding back geranylgeranyl pyrophosphate (GGPP), a key product of the mevalonate pathway, reversed the YAP bioactivity inhibition induced by simvastatin and the cell proliferation inhibition induced by the combination of simvastatin and EGFR inhibitors. Collectively, these results revealed that YAP may be useful in identifying cetuximab resistance in CRC and indicated that targeting of both YAP and EGFR signals may present a promising therapeutic approach for CRC.
\end{abstract}

\section{Introduction}

Colorectal cancer (CRC) is the third most common cancer worldwide (1). In recent years, $>1.2$ million patients have

Correspondence to: Professor Feng Bi, Department of Medical Oncology, West China Hospital, Sichuan University, 37 Wai Nan Guoxue Road, Chengdu, Sichuan 610041, P.R. China

E-mail: bifeng@scu.edu.cn

*Contributed equally

Key words: colorectal cancer,EGFR inhibitor, resistance, simvastatin, YAP been diagnosed annually and $\sim 600,000$ patients succumb to CRC every year (2). Surgical resection is the main method for treatment of early-stage CRC with a favorable prognosis. However, most patients are diagnosed with metastatic cancer, which is not suitable for resection. Traditional chemotherapy is the main approach for metastatic CRC (mCRC) and the overall survival can reach 15-19 months (3). With the advances in therapies, targeted drugs, such as cetuximab and bevacizumab, can prolong the overall survival to 28.7-33.1 months in mCRC patients $(4,5)$. Meanwhile, small EGFR tyrosine kinase inhibitors (TKIs), such as gefitinib and erlotinib, have been commonly used in non-small cell lung cancer and have improved progression-free survival, exhibiting great application potential. However, EGFR-inhibitor resistance has restricted their application, creating an urgent need to discover novel treatment strategies.

Yes-associated protein (YAP), a downstream effector of the Hippo pathway, is involved in tissue overgrowth and tumor formation (6). A study revealed that YAP could act as a transcriptional co-activator to promote the expression of genes involved in cell proliferation and apoptosis (7). A recent study revealed that YAP may be useful for identifying resistance to cetuximab (8). However, the role of YAP in cetuximab resistance remains elusive in $\mathrm{CRC}$.

In the present study, we observed that the expression of YAP was negatively associated with cetuximab sensitivity in CRC cell lines, independent of KRAS mutation status, and YAP knockdown enhanced the cytotoxicity of cetuximab. Simvastatin, a 3-hydroxy-3-methylglutaryl-coenzyme A (HMG-CoA) reductase inhibitor, has been reported to inhibit YAP bioactivity in multiple types of cancer cell lines $(9,10)$. We determined that simvastatin increased the sensitivity of CRC cells to cetuximab both in vitro and in vivo. These findings indicated that YAP may be useful in identifying cetuximab resistance in CRC cancer.

\section{Materials and methods}

Cell culture and agents. The CRC cell lines COLO 320, HCT 116, HT 29, SW 48, SW 480 and SW 1116 were purchased from the American Type Culture Collection (ATCC; Manassas, 
VA, USA). All cell lines were maintained in Dulbecco's modified Eagle's medium (DMEM; Gibco Laboratories; Thermo Fisher Scientific, Inc., Grand Island, NY, USA) supplemented with $10 \%$ heat-inactivated fetal bovine serum (FBS; Gibco; Thermo Fisher Scientific, Inc., Gaithersburg, MD, USA). Cell cultures were maintained with $100 \mathrm{U} / \mathrm{ml}$ of penicillin $\mathrm{G}$ sodium and $100 \mu \mathrm{g} / \mathrm{ml}$ streptomycin sulfate (Sigma-Aldrich; Merck KGaA, St. Louis, MO, USA) at $37^{\circ} \mathrm{C}$ in a humidified $5 \% \mathrm{CO}_{2}, 95 \%$ air incubator. Simvastatin was purchased from J\&K Scientific Ltd. (Beijing, China). Cetuximab was purchased from Merck \& Co., Inc. (Whitehouse Station, NJ, USA) and YM53601 was purchased from Cayman Chemical Company (Ann Arbor, MI, USA). Gefitinib, FTI277 and GGTI298 were purchased from Selleck Chemicals (Houston, TX, USA) and EGF and GGPP were purchased from Sigma-Aldrich; Merck KGaA.

Transfection. siRNAs against YAP and control siRNAs were designed and synthesized by Shanghai GenePharma Co., Ltd. (Shanghai, China). We used two independent siRNAs to target YAP. The siRNA sequence for YAP-1 was 5'-GACAUCUUC UGGUCAGAGA-3', the siRNA sequence for YAP-2 was 5'-CUGGUCAGAGAUACUUCUU-3' and the control siRNA sequence was 5'-AAUUCUCCGAACGUGUCACGUUU-3'. Cells were transfected with control siRNA and YAP siRNA for $72 \mathrm{~h}$ or at the indicated time-points using Lipofectamine 2000 (Invitrogen; Thermo Fisher Scientific, Inc., Waltham, MA, USA) according to the manufacturer's instructions.

Western blot analysis. Cells were lysed in ice-cold RIPA buffer containing protease inhibitor cocktail (Sigma-Aldrich; Merck KGaA). Cell lysates from mouse xenograft tumors (four groups) were homogenized and lysed in glass homogenizers in RIPA buffer. Subsequently, cell lysates were quantified with a BCA protein assay (Pierce Chemical Co., Dallas, TX, USA). Approximately $20 \mu \mathrm{g}$ of total protein was loaded onto a 10 or $12 \%$ SDS-PAGE gel, separated electrophoretically and then transferred to an NC membrane (EMD Millipore, Bedford, MA, USA). The membranes were blocked with $5 \%$ non-fat milk at room temperature for $\sim 30 \mathrm{~min}$ and then were washed three times with phosphate-buffered saline (PBS). Then, the membranes were incubated with the horseradish peroxidase conjugated anti-mouse (cat. no. HA1022) or anti-rabbit (cat. no. HA1001) secondary antibodies (Huabio, Hangzhou, China) with dilution of 1:5,000-1:10,000 at room temperature for $3 \mathrm{~h}$. Finally, the protein expression was detected with an Odyssey Infrared Imaging System (LI-COR Biosciences, Lincoln, NE, USA). Protein expression was quantified using ImageJ 1.48 (National institute of Health, Bethesda, MA, USA). Primary antibodies targeting the following proteins were used in the present study: pEGFR (cat. no. 3777), cyclin D1 (cat. no. 2922), YAP (cat. no. 4912), CYR61 (cat. no. 14479), PTEN (cat. no. 9552), GAPDH (cat. no. 97166) and Lamin B (cat. no. 13435), were purchased from Cell Signaling Technology (Danvers, MA, USA); EGFR (cat. no. sc-03-G) was purchased from Santa Cruz Biotechnology, Inc. (Dallas, TX, USA); and pAKT (cat. no. EP2109Y) and AKT (cat. no. EPR16798) were purchased from Abcam (Cambridge, UK). All the primary antibodies above were added at a 1:1,000 dilution at $4^{\circ} \mathrm{C}$ overnight.
Cell proliferation assay. Cells were seeded $\left(4 \times 10^{3}\right.$ cells/well in $100 \mu$ l DMEM with 10\% FBS) in a 96-well flat-bottomed plate (Corning Inc., Corning, NY, USA) $24 \mathrm{~h}$ before treatment. Following incubation, cell growth was determined with a Cell Counting Kit-8 (CCK-8; Dojindo Molecular Technologies, Inc., Kumamoto, Japan) assay following the manufacturer's instructions.

Hoechst 33342 staining. Cells were seeded $\left(4 \times 10^{3}\right.$ cells/well in $100 \mu \mathrm{l}$ DMEM with $10 \%$ FBS) in a 96-well flat-bottomed plate $24 \mathrm{~h}$ before treatment. Apoptotic cells were determined using Hoechst 33342 (Sigma-Aldrich; Merck KGaA) DNA staining according to the manufacturer's protocol. Apoptotic cells were detected by fluorescence microscopy (Nikon, Tokyo, Japan), which revealed nuclear condensation and DNA fragmentation.

Quantitative real-time PCR. Cells were collected in TRIzol (Invitrogen) for total RNA extraction according to the manufacturer's protocol. Retrotranscription was performed with Reverse Transcriptase M-MLV (Takara Biotechnology, Co., Ltd., Dalian, China). Real-time PCR reactions were performed with a SYBR Premix Ex Taq ${ }^{\mathrm{TM}}$ kit (Takara Biotechnology) on an iQ5 Real-Time PCR Detection system (Bio-Rad Laboratories, Inc., Hercules, CA, USA). The mixtures were incubated at $95^{\circ} \mathrm{C}$ for $10 \mathrm{~min}$, followed by 40 amplification cycles of $95^{\circ} \mathrm{C}$ for $20 \mathrm{sec}, 55-65^{\circ} \mathrm{C}$ for $20 \mathrm{sec}$ and $72^{\circ} \mathrm{C}$ for $30 \mathrm{sec}$. The primers used were as follows: YAP sense, $5^{\prime}-\mathrm{GGT}$ GCCACTGTTAAGGAAAGG-3' and antisense, 5'-GTGAGG CCACAGGAGTTAGC-3'; CTGF sense, 5'-TGGTGCAGC CAGAAAGCTC-3' and antisense, 5'-CCAATGACAACG CCTCCTG-3'; CYR61 sense, 5'-TTCTTTCACAAGGCG GCACTC-3' and antisense, 5'-AGCCTCGCATCCTATACA ACC-3'; GAPDH sense, 5'-CAAGGCCAACCGCGAGAA-3' and antisense, 5'-CCCTCGTAGATGGGCACAGT-3'. The data were analyzed with the $2^{-\Delta \Delta C q}$ method (11).

Nuclear and cytoplasmic protein extraction. After the addition of reagents as indicated, nuclear and cytoplasmic proteins from cells and mouse xenograft tumors were extracted with a Nuclear and Cytoplasmic Extraction kit (Thermo Fisher Scientific, Inc., Waltham, MA, USA) according to the manufacturer's instructions.

Immunofluorescence. Approximately $4 \times 10^{3}$ cells were seeded on a 24-well culture dish. After the addition of reagents, the cells were fixed with PBS-buffered $4 \%$ paraformaldehyde for 10 min followed by permeabilization with $0.3 \%$ Triton X-100 for $10 \mathrm{~min}$ and blocking with $3 \% \mathrm{BSA}$ for $30 \mathrm{~min}$. The primary antibody (YAP) was added at a 1:75 dilution in PBS overnight at $4^{\circ} \mathrm{C}$, followed by three PBS washes. The secondary FITC-labeled antibody (cat. no. 31568) (Invitrogen; Thermo Fisher Scientific, Inc.) at a 1:75 dilution in PBS was then incubated with cells for $2 \mathrm{~h}$ at $37^{\circ} \mathrm{C}$. After three PBS washes, immunofluorescence was viewed with a fluorescence microscope (Eclipse TE300; Nikon, Tokyo, Japan). All procedures were performed at room temperature unless otherwise specified.

In vivo assay and ethical standards. Four-week-old female BALB/c nude mice obtained from Beijing HFK 

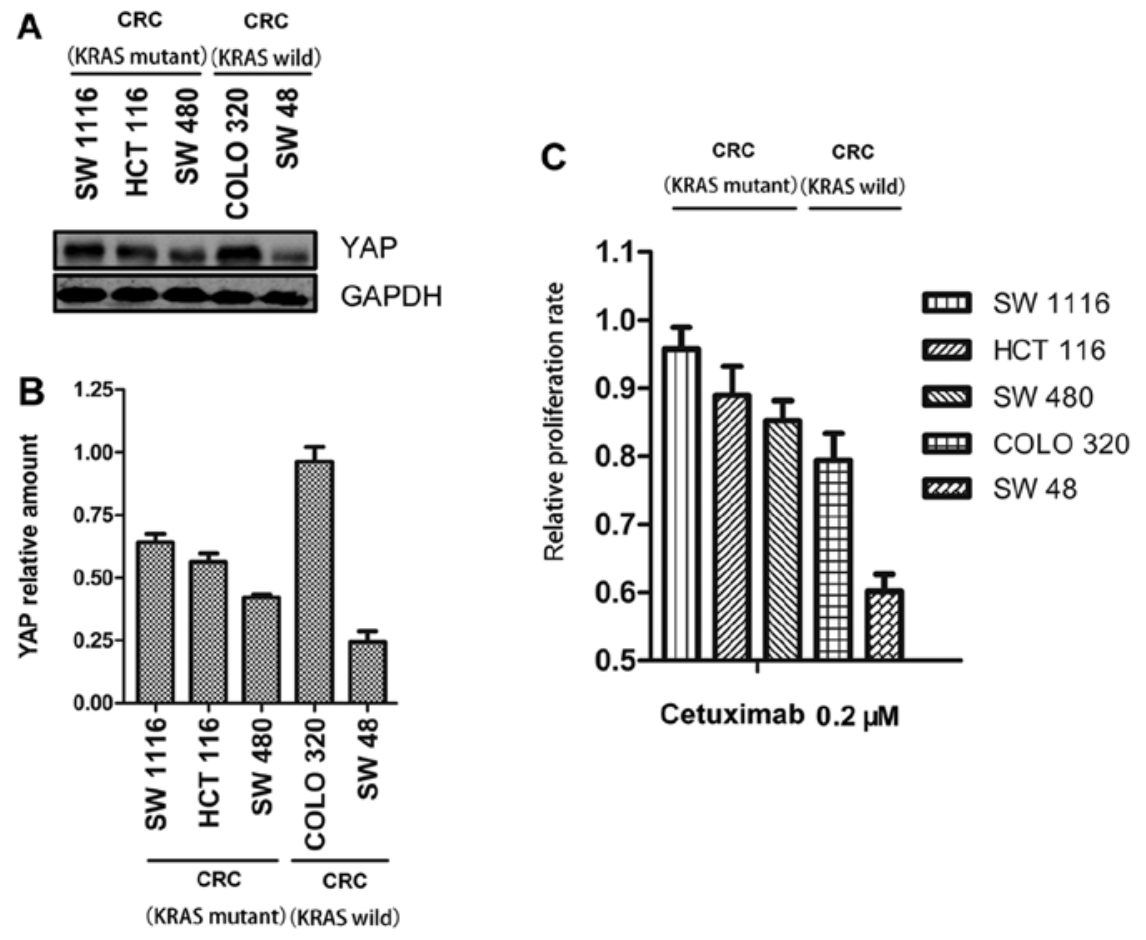

Figure 1. YAP expression is negatively associated with the sensitivity of colorectal cells to cetuximab. (A) Levels of YAP were determined by immunoblotting analysis in five cell lines and GAPDH was used as the control. Representative results are shown. (B) Relative levels of YAP compared with GAPDH were determined via immunoblotting analysis in five cell lines. (C) Relative proliferation rate: Cells treated with cetuximab were compared with each untreated cell line separately. Cell proliferation was determined with CCK-8 assays of five cell lines treated with $0.2 \mu \mathrm{M}$ cetuximab for $48 \mathrm{~h}$ in $0.5 \%$ FBS. All the data are presented as the means $\pm \mathrm{SEM} ; \mathrm{n}=3$ biological replicates. YAP, yes-associated protein.

Biotechnology Co., Ltd. (Beijing, China) were maintained under specific pathogen-free conditions. Mice were injected subcutaneously with SW 480 cells. When the xenografts reached a volume of $80-100 \mathrm{~mm}^{3}$, the mice (five mice per group) were assigned into four groups (control, cetuximab, simvastatin and cetuximab + simvastatin). The mice were treated with intraperitoneal injection of $20 \mathrm{mg} / \mathrm{kg}$ cetuximab in dimethyl sulfoxide (DMSO) once every 3-4 days and/or orally with $6 \mathrm{mg} / \mathrm{kg}$ simvastatin in DMSO once daily. Tumor diameters were determined with a digital caliper every three days following treatment. All animal experimental procedures used in the present study were approved by the Experimental Animal Manage Committee of West China Hospital, Sichuan University under contract 2016003A and were performed strictly according to the guidelines of the Animal Ethics Committee Guidelines of the Animal Facility of West China Hospital and the Animal Care and Use Committee of Sichuan University.

Statistical analysis. Values are presented as the means \pm standard error of the mean (SEM). All statistical analyses were performed with SPSS 14.0 software for Windows (SPSS, Inc., Chicago, IL, USA). Correlation analysis between the expression of YAP and proliferation inhibition rate was performed by Spearman's correlation test as previously described (12). Student's t-test was performed when two groups were compared; one-way ANOVA and post hoc Tukey's test were performed when multiple comparisons were conducted. $\mathrm{P}<0.05$ was considered to indicate a statistically significant result.

\section{Results}

YAP expression is negatively associated with the sensitivity of CRC cells to cetuximab. First, we examined YAP expression in five CRC cell lines (SW 1116, HCT 116, SW 480, COLO 320 and SW 48). Since KRAS mutation status is reported as an independent biomarker for cetuximab efficacy (13), we divided the cancer cells into two groups, wild-type KRAS CRC cell lines and mutant KRAS CRC cell lines. Subsequently, we investigated whether YAP participated in cetuximab resistance in vitro. We assessed the relative expression of YAP compared with the expression of GAPDH in the five cell lines. The relative YAP expression of the mutant KRAS CRC cell lines (SW 1116, HCT 116 and SW 480) were 0.64, 0.56 and 0.42 , respectively; and that of the wild-type KRAS CRC cell lines (COLO 320 and SW 48) were 0.96 and 0.24, respectively (Fig. 1A and B). Subsequently, we determined the relative proliferation rate of each cell line treated with cetuximab compared with each untreated cell line, separately. We observed that SW 1116 and COLO 320, which had the highest YAP expression in each group, demonstrated the lowest sensitivity to cetuximab (Fig. 1C). SW 480 and SW 48 cell lines had the lowest YAP levels and the highest sensitivity to cetuximab in each group (Fig. 1C). The relative proliferation rate of the mutant KRAS CRC cell lines was 0.96 vs. 0.85 for SW 1116 vs. SW 480 , and 0.79 vs. 0.60 for the wild-type KRAS CRC cell lines COLO 320 vs. SW 48 . We then conducted a correlation analysis to determine statistical relationships involving YAP expression and rate of proliferation inhibition against cetuximab. The correlation coefficients of the mutant KRAS 
A

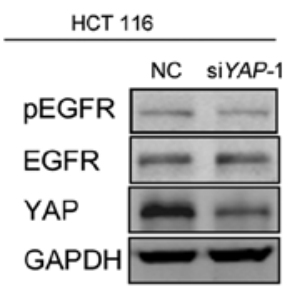

C



E
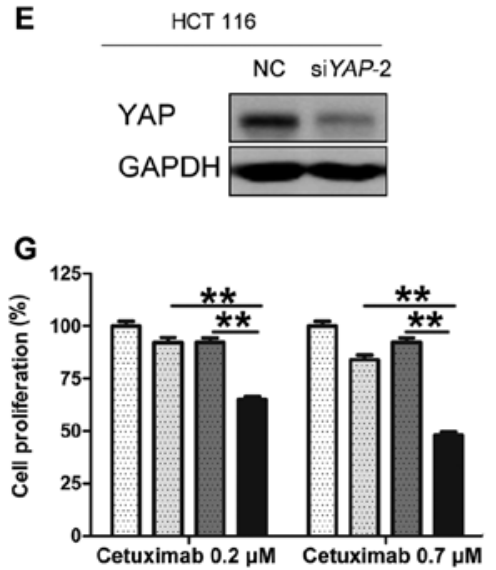

B

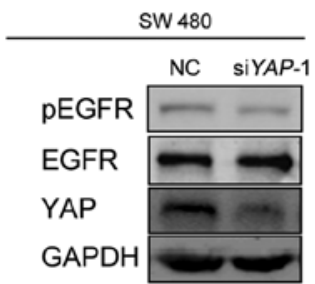

D

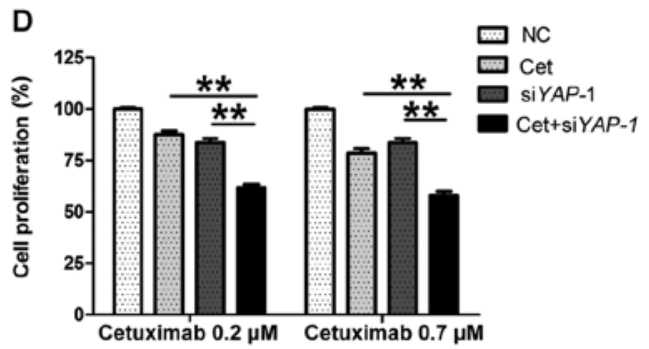

$\mathbf{F}$

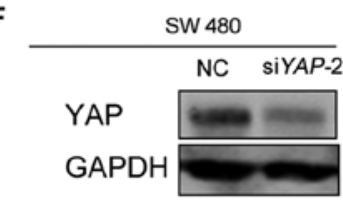

$\mathrm{H}$

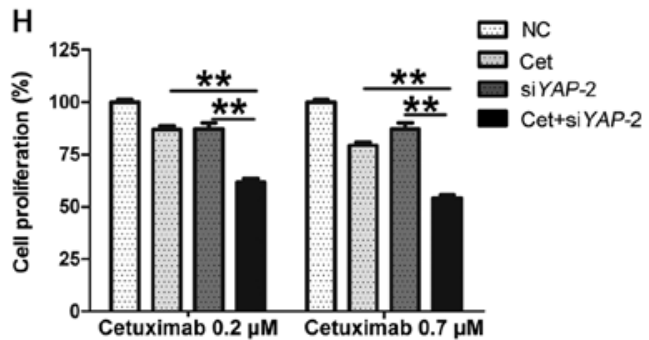

I HCT 116

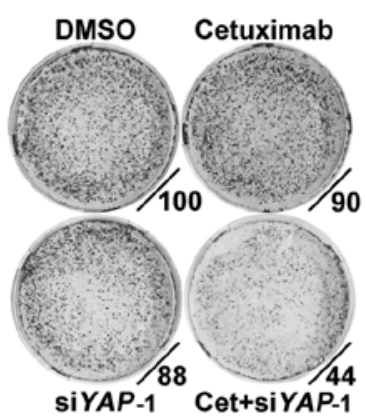

SW 480

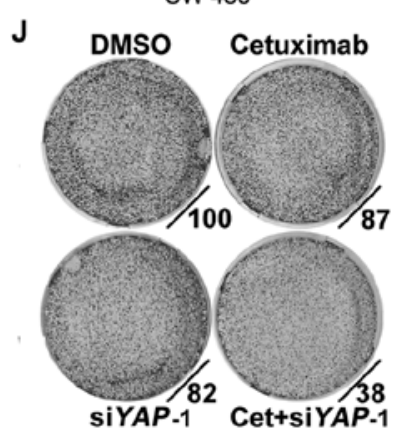

Figure 2. YAP knockdown enhances the sensitivity of CRC cell lines to cetuximab. (A, B, E and F) HCT 116 and SW 480 cells were transfected with NC or siYAP (siYAP-1 and siYAP-2) for $72 \mathrm{~h}$. Immunoblotting analyses were then performed with the indicated antibodies. (C, D, G and H) Effects of YAP knockdown on sensitivity to cetuximab in HCT 116 and SW 480 cells. Cell proliferation was determined with CCK-8 assays following YAP knockdown for 72 h and cetuximab treatment for $48 \mathrm{~h}$. (I and J) Colony formation of HCT 116 and SW 480 cells treated with DMSO, $0.2 \mu \mathrm{M}$ cetuximab, siYAP-1, or a combination of $0.2 \mu \mathrm{M}$ cetuximab and siYAP-1 for 7 days in $0.5 \%$ FBS. Cells were stained with $0.1 \%$ crystal violet. All the data are presented as the means \pm SEM; $n=3$ biological replicates. One-way ANOVA and post hoc Tukey's test were performed. ${ }^{* *} \mathrm{P}<0.01$. YAP, yes-associated protein; NC, control; Cet, cetuximab.

CRC cell lines and wild-type KRAS cell lines were 0.83 and $0.89(\mathrm{P}<0.05)$, respectively. Collectively, these results indicated that cetuximab sensitivity was negatively correlated with YAP expression independent of KRAS mutation status.

YAP knockdown enhances the sensitivity of CRC cell lines to cetuximab. To further investigate the effect of YAP on the sensitivity of cancer cell lines to cetuximab, we transfected cells with two independent RNA interference constructs (siYAP-1 and siYAP-2) (Fig. 2A and B, E and F). We selected two cell lines with primary cetuximab resistance, namely, HCT 116 and SW 480 (Fig. 1C), to conduct the following study. The results revealed that the combination of cetuximab and siYAP-1 significantly reduced cell proliferation compared with cetuximab or siYAP-1 alone (HCT 116, $0.7 \mu \mathrm{M}$ cetuximab vs. $0.7 \mu \mathrm{M}$ cetuximab + siYAP-1, mean relative cell proliferation rate: 83.5 vs. $49.9 \%, \mathrm{P}<0.01$; SW $480,0.7 \mu \mathrm{M}$ cetuximab vs. $0.7 \mu \mathrm{M}$ cetuximab + siYAP-1, mean relative cell proliferation rate: 78.3 vs. $57.9 \%, \mathrm{P}<0.01$ ) (Fig. $2 \mathrm{C}$ and $\mathrm{D}$ ). In addition, results involving siYAP-2 revealed a similar trend (Fig. 2G and H). Furthermore, colony formation assays revealed that knockdown of YAP-1 promoted colony inhibition caused by cetuximab (Fig. 2I and J). These results indicated that YAP may be related to primary resistance to cetuximab.

Simvastatin inhibits YAP bioactivity through total YAP expression and nuclear translocation. Simvastatin, an HMG-CoA reductase inhibitor, is widely used to lower cellular cholesterol levels in patients with hypercholesterolemia (10). To investigate the effects of simvastatin on YAP bioactivity, we first detected the total YAP protein expression. We observed that simvastatin treatment caused the total YAP protein level to decrease in a dose-dependent manner (Fig. 3A and B). Furthermore, real-time PCR results revealed that simvastatin treatment did not change the YAP mRNA level (Fig. 3C and D). YAP subcellular localization is also important for its bioactivity, as only nuclear YAP can interact with TEAD1-4 transcription factors and execute its function as a transcriptional co-activator. Thus, we analyzed the effects of simvastatin on YAP localization via immunofluorescence, and the results indicated that simvastatin treatment caused a significant decrease in YAP presence in the 
A

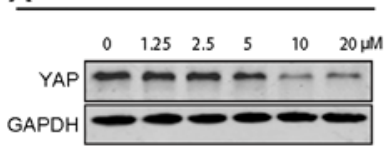

C

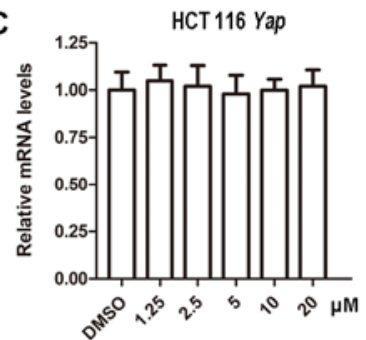

B

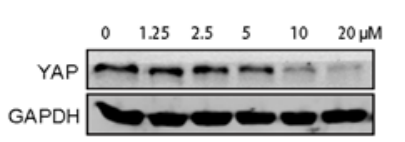

D

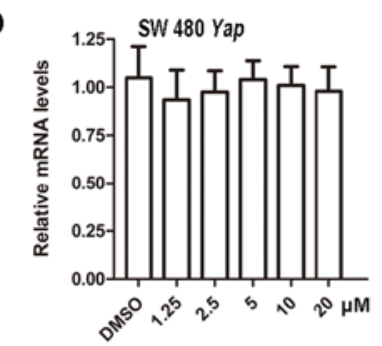

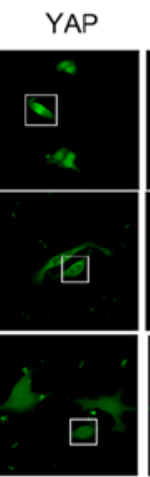

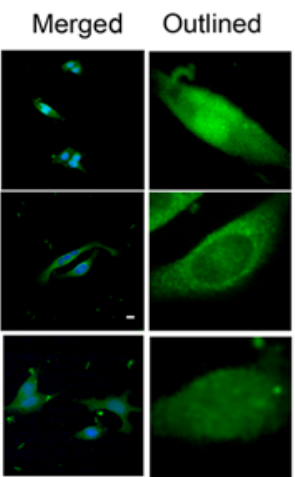

$F$
$\stackrel{5}{5}$
$\frac{5}{5}$
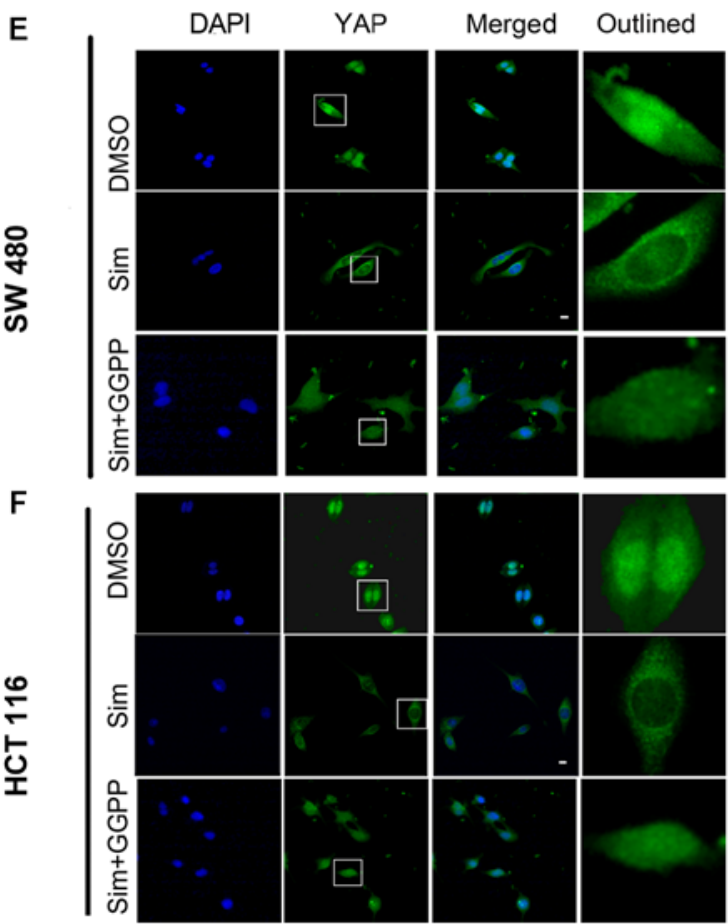

G

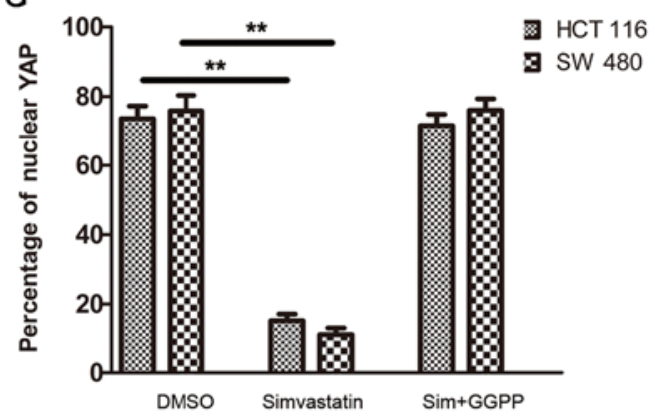

H

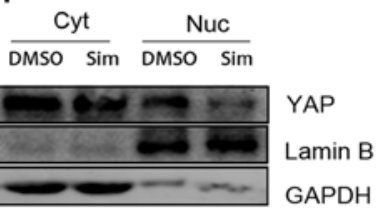

I SW 480


$\square$ DMSO

- 1.25

ㅁ 2.5

四 5

메 10

alv $20 \mu \mathrm{M}$

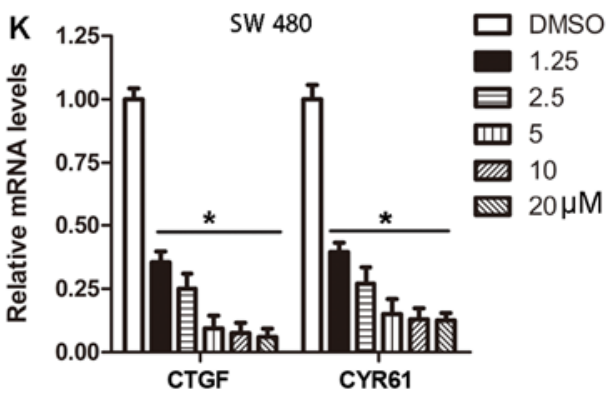

Figure 3. Simvastatin inhibits YAP bioactivity through total YAP expression and nuclear translocation. (A and B) Total YAP levels determined by immunoblotting of HCT 116 and SW 480 cells following treatment with $0-20 \mu \mathrm{M}$ simvastatin for $48 \mathrm{~h}$. (C and D) Cells were treated with DMSO or the indicated concentration of simvastatin for $48 \mathrm{~h}$. YAP mRNA levels were assessed via real-time PCR in HCT 116 and SW 480 cells. DMSO was used as the control. (E and F) Cells were treated with DMSO, $10 \mu \mathrm{M}$ Sim or $10 \mu \mathrm{M}$ simvastatin $+10 \mu \mathrm{M}$ GGPP for $48 \mathrm{~h}$. Representative images of YAP subcellular localization (cytoplasm or nucleus) identified by immunofluorescence are displayed. Scale bar, $10 \mu \mathrm{m}$. (G) Percentage of cells with nuclear YAP localization following treatment with DMSO, $10 \mu \mathrm{M}$ simvastatin or $10 \mu \mathrm{M}$ simvastatin $+10 \mu \mathrm{M}$ GGPP for $48 \mathrm{~h}$. At least 100 cells were scored in every replicate. (H and I) Cells were treated with DMSO or $10 \mu \mathrm{M}$ Sim for $48 \mathrm{~h}$. Levels of YAP in the cytoplasm and nuclei of HCT 116 and SW 480 cells. GAPDH and Lamin B were used as loading controls for the cytoplasm and nucleus, respectively. ( $\mathrm{J}$ and $\mathrm{K}$ ) Cells were treated with DMSO or the indicated concentrations of simvastatin for 48 h. CTGF and CYR61 mRNA levels were measured via real-time PCR in HCT 116 and SW 480 cells. All the data are displayed as the means \pm SEM; $\mathrm{n}=3$ biological replicates. Two-tailed Student's t-test was used throughout. " $\mathrm{P}<0.05,{ }^{* *} \mathrm{P}<0.01$. YAP, yes-associated protein; DMSO, dimethyl sulfoxide; Sim, simvastatin.

nucleus (HCT 116, DMSO vs. simvastatin, mean percentage of nuclear YAP was 73.6 vs. 15.2\%, P<0.01; SW 480, DMSO vs. simvastatin, mean percentage of nuclear YAP was 75.8 vs. $11.2 \%, \mathrm{P}<0.01$ ) (Fig. 3E, F and G). Following the addition of geranylgeranyl pyrophosphate (GGPP), the effects of simvastatin on nuclear YAP were partly reversed (Fig. 3E, F and G). Western blot analysis also revealed that the nuclear YAP level significantly decreased following simvastatin treatment (Fig. 3H and I). In addition, experiments revealed that simvastatin inhibited the downstream targets of YAP, namely, CYR61 and CTGF, at the mRNA level (Fig. 3J and K). Collectively, these results indicated that simvastatin could act as a YAP inhibitor through the inhibition of the expression of YAP and nuclear translocation.

Simvastatin increases the antitumoractivity of EGFR inhibitors in CRC cell lines. To investigate the antitumor effects of simvastatin and (or) cetuximab, cell proliferation was assessed. 



E
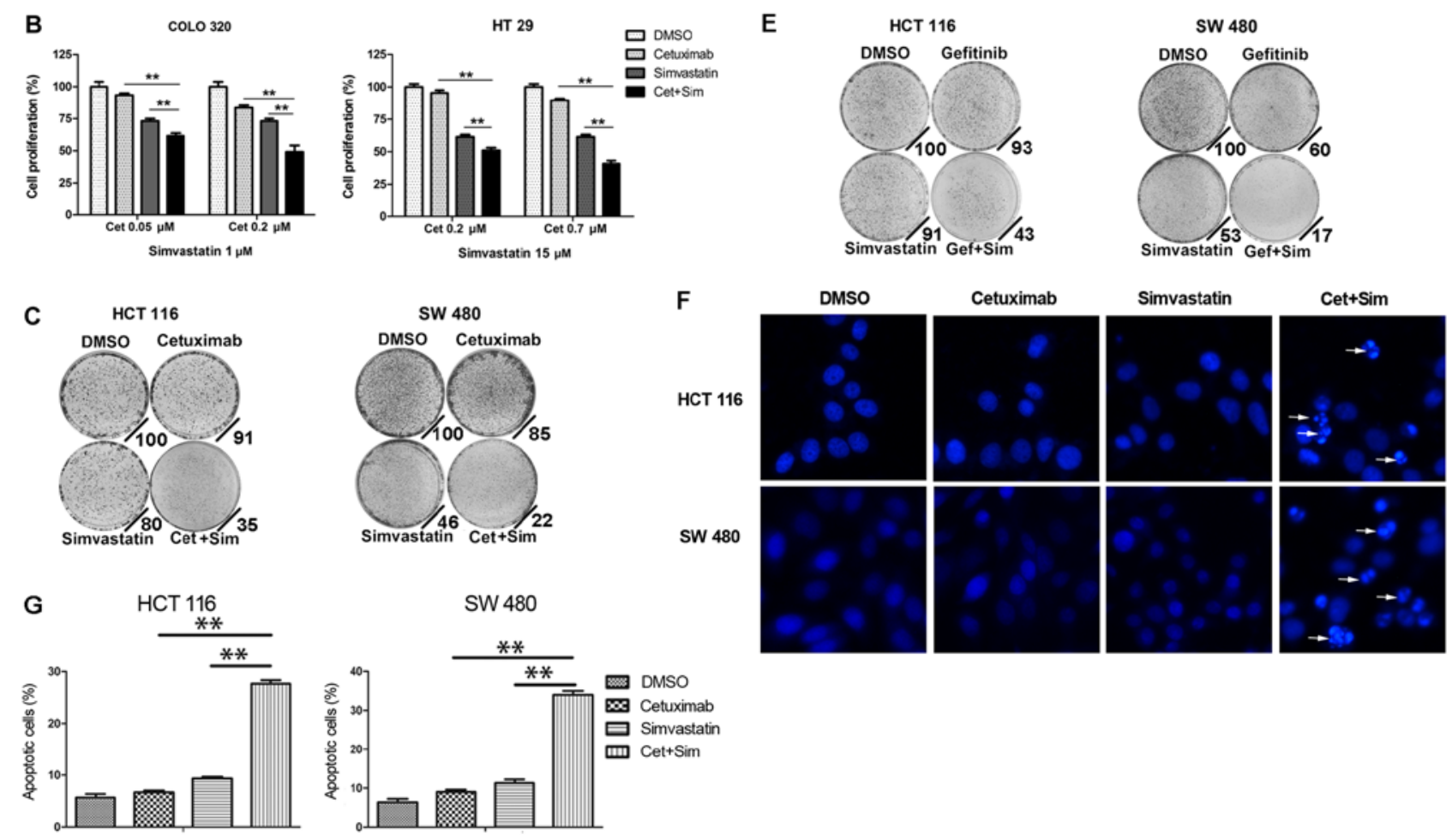

Figure 4. Simvastatin increases the antitumor activity of EGFR inhibitors in CRC cells. (A, B and D) Cell proliferation was determined with CCK-8 assays of CRC cells treated with the indicated agents (concentration indicated) for $48 \mathrm{~h}$. One-way ANOVA and post hoc Tukey's tests were performed. (C) Colony formation of HCT 116 and SW 480 cells treated with DMSO, $0.2 \mu \mathrm{M}$ cetuximab, $3 \mu \mathrm{M}$ simvastatin, or a combination of $0.2 \mu \mathrm{M}$ cetuximab and $3 \mu \mathrm{M}$ simvastatin for 7 days in $0.5 \%$ FBS and stained with $0.1 \%$ crystal violet. (E) Colony formation of HCT 116 and SW 480 cells treated with DMSO, $3 \mu$ M (HCT 116) or $6 \mu \mathrm{M}$ (SW 480) gefitinib, $1 \mu \mathrm{M}$ simvastatin, or a combination of gefitinib and $1 \mu \mathrm{M}$ simvastatin for 5 days in $10 \%$ FBS. Cells were stained with $0.1 \%$ crystal violet. (F and G) Cell apoptosis assessed by Hoechst staining of HCT 116 and SW 480 cells treated with DMSO, $0.2 \mu$ M cetuximab, $3 \mu$ M simvastatin, or a combination of $0.2 \mu \mathrm{M}$ cetuximab and $3 \mu \mathrm{M}$ simvastatin for $48 \mathrm{~h}$ in $0.5 \% \mathrm{FBS}$. Representative immunofluorescence images are shown. Apoptoticc cells (white arrows). (G) At least 100 cells were scored in every replicate. All the data are shown as the means \pm SEM except when otherwise indicated; $n=3$ biological replicates. ${ }^{*} \mathrm{P}<0.05,{ }^{* * *} \mathrm{P}<0.01$. CRC, colorectal cancer; DMSO, dimethyl sulfoxide; Cet, cetuximab; Gef, gefitinib; Sim, simvastatin.

Compared with single agents, cetuximab + simvastatin demonstrated more significant proliferation inhibition (HCT 116, $0.7 \mu \mathrm{M}$ cetuximab vs. $0.7 \mu \mathrm{M}$ cetuximab $+3 \mu \mathrm{M}$ simvastatin, mean relative cell proliferation rate $=83.4$ vs. $61.8 \%, \mathrm{P}<0.01$; SW $480,0.7 \mu \mathrm{M}$ cetuximab vs. $0.7 \mu \mathrm{M}$ cetuximab $+3 \mu \mathrm{M}$ simvastatin, mean relative cell proliferation rate $=78.4$ vs. $52.5 \%$, $\mathrm{P}<0.01$ ) (Fig. 4A). Similar results were observed in COLO 320 and HT 29 cell lines (Fig. 4B). Additionally, colony formation assays demonstrated that the combination of simvastatin and cetuximab achieved greater colony inhibition than single agents (Fig. 4C). Subsequently, Hoechst staining indicated that cetuximab + simvastatin induced apoptosis more strongly than each agent alone (Fig. 4F and G). Collectively, these results revealed that simvastatin increased the cytotoxicity of cetuximab against CRC cells. To investigate whether simvastatin could enhance the cytotoxicity of gefitinib, a further combination of simvastatin with gefitinib was examined, and the results revealed greater cytotoxicity and colony inhibition compared with each drug alone (HCT 116, $6 \mu \mathrm{M}$ gefitinib vs. $6 \mu \mathrm{M}$ gefitinib $+1 \mu \mathrm{M}$ simvastatin, mean relative cell proliferation rate: 40.3 vs. $19.0 \%, \mathrm{P}<0.01$; SW $480,12 \mu \mathrm{M}$ gefitinib vs. $12 \mu \mathrm{M}$ gefitinib $+1 \mu \mathrm{M}$ simvastatin, mean relative cell proliferation rate: 48.7 vs. $28.1 \%, \mathrm{P}<0.01$ ) (Fig. $4 \mathrm{D}$ and $\mathrm{E}$ ). These results indicated that simvastatin could increase the cytotoxicity of EGFR inhibitors (cetuximab and gefitinib) against CRC cells. To further investigate the effect of the combined strategy on tumor growth, we implanted SW 480 cells in nude mice and divided these mice into four groups (control, cetuximab, simvastatin and cetuximab + simvastatin). Consistent with the in vitro results, the combination of cetuximab and simvastatin caused significant inhibition of tumor growth compared with cetuximab (cetuximab vs. cetuximab + simvastatin, and the mean tumor volumes [Volume $=\left(\mathrm{L} \mathrm{x} \mathrm{W}^{2}\right) / 2, \mathrm{~L}=$ length and $\mathrm{W}=$ width] were $648.1 \pm 143.3 \mathrm{~mm}^{3}$ (mean $\pm \mathrm{SEM}$ ) vs. $310.3 \pm 67.7 \mathrm{~mm}^{3}, \mathrm{P}<0.01$ ) (Fig. $5 \mathrm{C}$ and D). Simvastatin had no obvious impact on the daily movements or the weights of mice. 
A

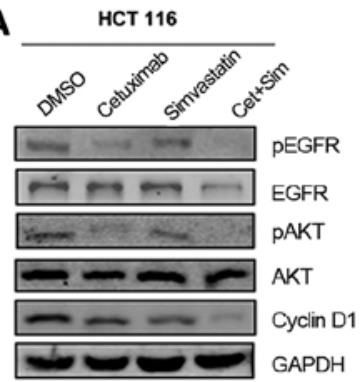

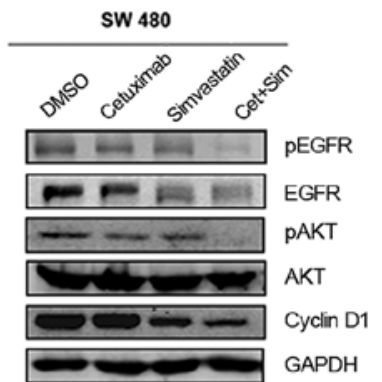

C



B

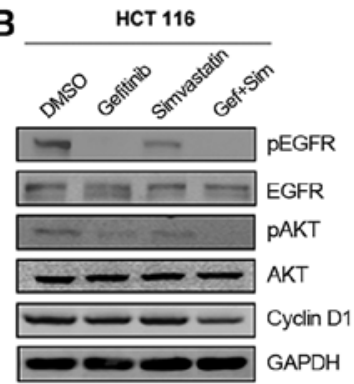

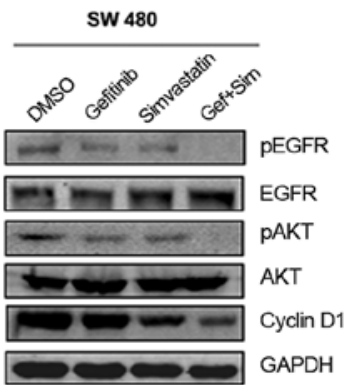

D



Xenografts of SW $\mathbf{4 8 0}$ nude mice
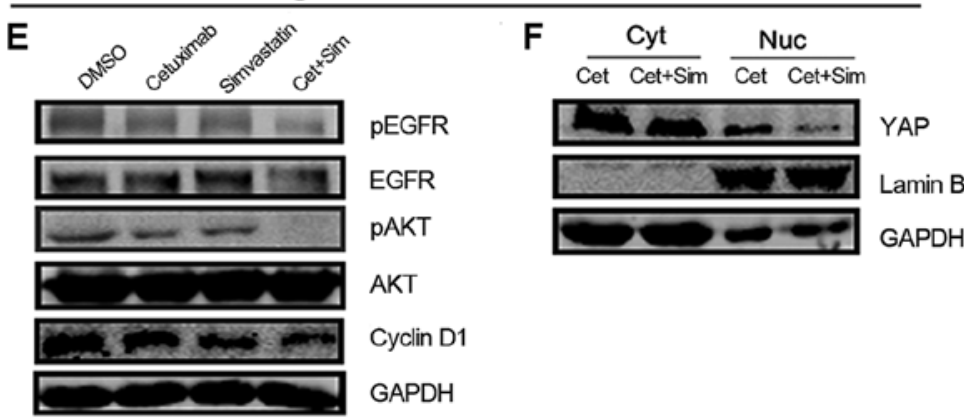

Figure 5. Simvastatin increases the antitumor activity of cetuximab and gefitinib. (A and B) Effect of simvastatin, cetuximab (or gefitinib), or a combination of simvastatin and cetuximab (or gefitinib) on the EGFR signaling pathway and cyclin D1 were determined by immunoblotting analysis. Cells were treated with DMSO, $0.2 \mu \mathrm{M}$ cetuximab (or $10 \mu \mathrm{M}$ gefitinib), $10 \mu \mathrm{M}$ simvastatin, or a combination of $0.2 \mu \mathrm{M}$ cetuximab (or $10 \mu \mathrm{M}$ gefitinib) and $10 \mu \mathrm{M}$ simvastatin for 48 h. (C) Graphical representation of SW 480 cell-derived tumor volumes on different days following treatment (four groups). The error bars represent the $95 \%$ confidence intervals of the mean volume. Two-tailed Student's t-test was performed. (D) Representative SW 480 xenograft tumors were resected on day 16 after treatment with the indicated agents. Agent concentrations are shown in the Materials and methods section. Scale bar, $10 \mathrm{~mm}$. (E) Effects of simvastatin, cetuximab, or the combination of simvastatin and cetuximab on the EGFR signaling pathway and cyclin D1 in vivo were determined by immunoblotting analysis. (F) BALB/c nude mice were treated with cetuximab or a combination of simvastatin and cetuximab. Levels of YAP in the cytoplasm or nucleus of SW 480 tumor cells were determined via immunoblotting analysis. GAPDH and Lamin B were used as loading controls for the cytoplasm and nucleus, respectively. All the data are shown as the means \pm SEM; $n=3$ biological replicates. Cyt, cytoplasm; Nuc, nucleus; Cet, cetuximab; Sim, simvastatin.

In addition, we did not observe any severe side effects in the mice.

Effects of simvastatin and EGFR inhibitors on EGFR signaling and cyclin D1. We then detected the effects of simvastatin and EGFR inhibitors on EGFR pathway signaling. Western blot analysis revealed that simvastatin treatment inhibited pEGFR and pAKT. The combination of cetuximab with simvastatin caused additional inhibition of pEGFR and pAKT compared with cetuximab alone (Fig. 5A). Additionally, the combination of simvastatin and gefitinib revealed a similar trend in pEGFR and pAKT inhibition (Fig. 5B). Subsequently, we analyzed the expression levels of cyclin D1, a protein related to proliferation. The results revealed that the combination of simvastatin and EGFR inhibitors caused an additional decrease in cyclin D1 compared with single agents (Fig. 5A and B). Consistent with the in vitro results, we observed a similar trend in the expression of pEGFR, pAKT and cyclin D1 in SW 480 xenograft tumors (Fig. 5E). Cetuximab + simvastatin treatment markedly reduced nuclear YAP levels compared with cetuximab alone in vivo (Fig. $5 \mathrm{~F})$.

Simvastatin inhibition of EGFR-AKT signaling may be mediated through GGPP. To determine the internal mechanism of pAKT inhibition caused by simvastatin, we hypothesized that simvastatin could inhibit the expression of pAKT through EGFR, which acts upstream of AKT and (or) acceleration of phosphatase and tensin homolog (PTEN), which negatively regulates the PI3K/AKT signaling pathway. We observed that EGF-activated pEGFR and pAKT signaling was markedly decreased following simvastatin treatment compared with the EGF control group, while the expression of PTEN was nearly unchanged (Fig. 6A and B). GGPP, a key product of the mevalonate pathway, reversed the decrease in pEGFR and pAKT caused by simvastatin (Fig. 6C and D, lanes 5 and 8). Since simvastatin is an inhibitor of the mevalonate pathway and 
A

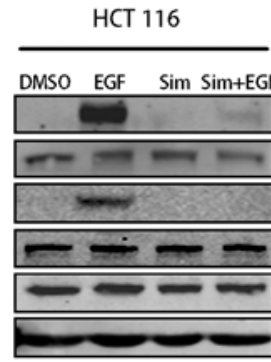

PEGFR

EGFR

PAKT

AKT

PTEN

GAPDH

B



E

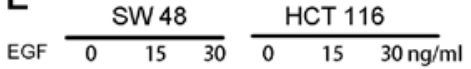

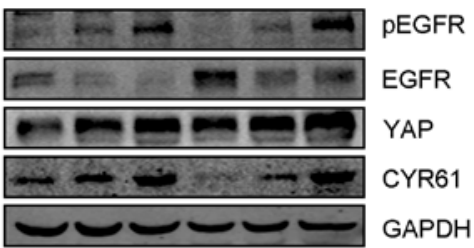

C



D

SW 480

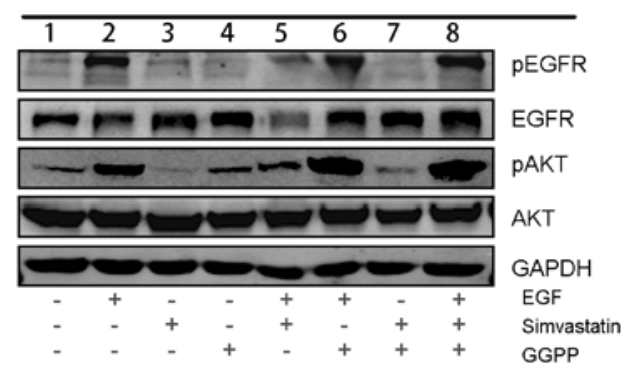

$\mathbf{F}$

SW 48

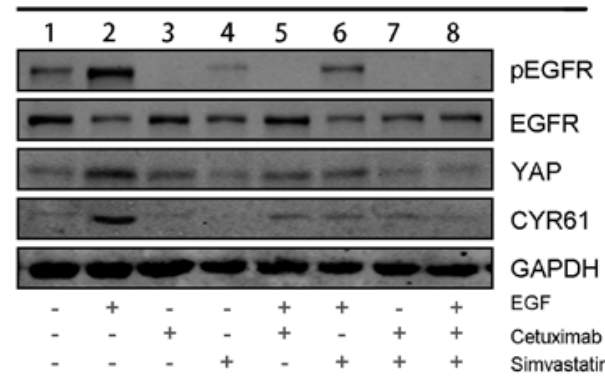

Figure 6. Simvastatin inhibits EGF-induced AKT phosphorylation and YAP activation through EGFR. (A and B) Simvastatin inhibited EGF-induced AKT phosphorylation through EGFR. HCT 116 and SW 480 cells were cultured in serum-free medium for $24 \mathrm{~h}$. Then, $10 \mu \mathrm{M}$ simvastatin was added to treat the cells for $48 \mathrm{~h}$. Before protein extraction, the cultures were exposed to $30 \mathrm{ng}$ EGF for $30 \mathrm{~min}$, as indicated. (C and D) Simvastatin inhibited the EGFR/AKT pathway through GGPP. HCT 116 and SW 480 cells were cultured in serum-free medium for $24 \mathrm{~h}$. Then, the cells were treated with $10 \mu \mathrm{M}$ simvastatin and (or) $10 \mu \mathrm{M}$ GGPP for $48 \mathrm{~h}$. Before protein extraction, cultures were exposed to $30 \mathrm{ng}$ EGF for $30 \mathrm{~min}$, as indicated. (E) EGF promoted YAP activity. SW 48 (left) and HCT 116 (right) cells were cultured in serum-free medium for $24 \mathrm{~h}$. Subsequently, the cells were treated with 0-30 ng EGF for $2 \mathrm{~h}$. (F) Combination of cetuximab and simvastatin inhibited EGF-promoted YAP activity more thoroughly than single agents. SW 48 cells were cultured in serum-free medium for $24 \mathrm{~h}$. Subsequently, cells were treated with $10 \mu \mathrm{M}$ simvastatin and (or) $0.2 \mu \mathrm{M}$ cetuximab for $48 \mathrm{~h}$. Prior to protein extraction, cultures were exposed to $30 \mathrm{ng}$ EGF for $30 \mathrm{~min}$, as indicated. $\mathrm{n}=3$ biological replicates. DMSO was used as the control. GAPDH was used as the loading control. GGPP, geranylgeranyl pyrophosphate; YAP, yes-associated protein; DMSO, dimethyl sulfoxide; Sim, simvastatin.

simvastatin treatment inhibits synthesis of GGPP $(9,10)$, these results indicated that the simvastatin-induced inhibition of the EGFR/AKT pathway may be mediated through the mevalonate pathway product GGPP.

EGF promotes YAP bioactivity in some CRC cells. Recent studies have revealed that crosstalk between the Hippo pathway and other signaling pathways plays a vital role in carcinogenesis and drug resistance $(13,14)$. In the present study, we particularly studied the interaction between YAP, an effector of the hippo pathway, and EGFR in CRC cells, and the data indicated that YAP knockdown nearly had no effect on the expression of pEGFR (Fig. 2A and B). Notably, EGF promoted YAP expression and that of its direct downstream target CYR61 in a dose-dependent manner in SW 48 and HCT 116 cells (Fig. 6E). When we blocked EGFR signaling with cetuximab, we observed that cetuximab reversed the EGF-induced increase in YAP and CYR61 (Fig. 6F, lanes 1, 2 and 5). Furthermore, when we combined cetuximab and simvastatin, YAP and
CYR61 were inhibited more markedly than with cetuximab alone following EGF activation (Fig. 6F, lanes 5 and 8). These results indicated that activation of EGFR signaling can promote YAP signaling in some CRC cells, and a combination of cetuximab and simvastatin can inhibit YAP signaling more thoroughly than single treatment.

The GGPP pathway mainly mediates the combined effect of simvastatin and EGFR inhibitors. The mevalonate pathway plays an important role in the tumorigenesis of many cancers (14). To determine detailed information about which signaling branch of the mevalonate pathway, primarily mediates the combined therapy effect, we used three different inhibitors, FTI277, YM53601 and GGTI298, to inhibit farnesyl transferase, squalene synthase and geranylgeranyl transferase, respectively (Fig. 7A). The combination of FTI277 or YM53601 with EGFR inhibitors had no significant effect on cell proliferation compared with EGFR inhibitors alone (Fig. 7C, E, H and J). Adding back squalene, the product of squalene synthase, could not reverse 
A

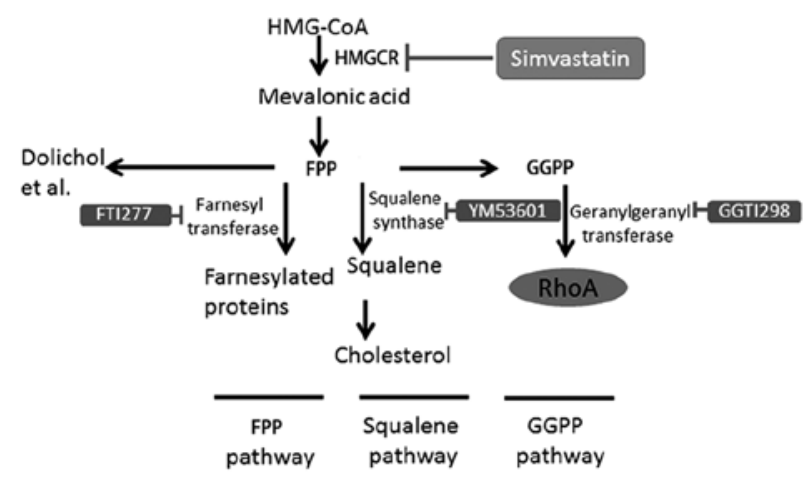

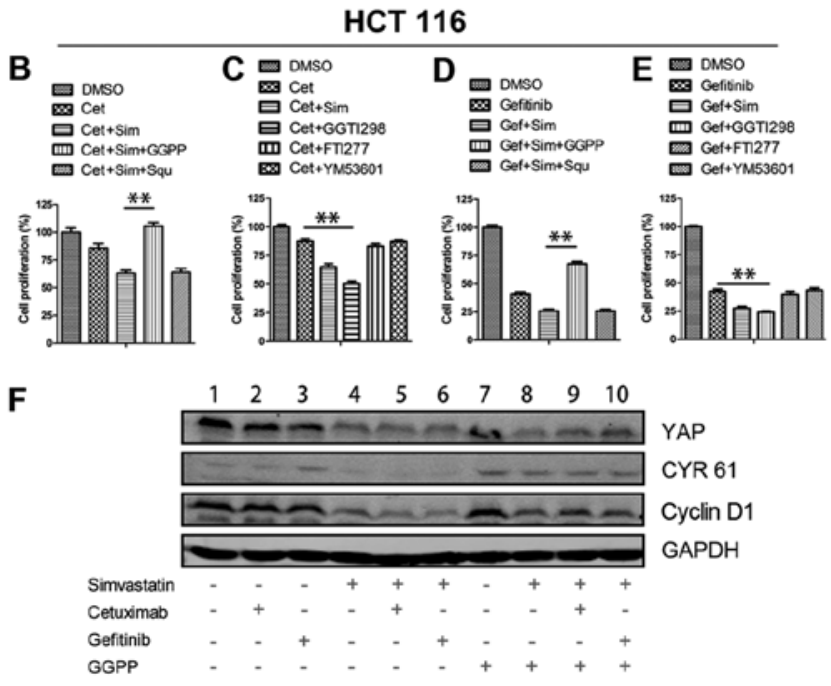



Figure 7. The GGPP pathway mainly mediates the combined effect of simvastatin and EGFR inhibitors. (A) Overview of the mevalonate pathway. $(\mathrm{B}, \mathrm{C}, \mathrm{G}$ and $\mathrm{H})$ Cell proliferation was determined with CCK-8 assays of HCT 116 and SW 480 cells treated with the indicated agents for $48 \mathrm{~h}$ in $0.5 \% \mathrm{FBS}$. The concentrations of agents were as follows: cetuximab $0.7 \mu \mathrm{M}$, simvastatin $3 \mu \mathrm{M}$, GGPP $10 \mu \mathrm{M}$, squalene $10 \mu \mathrm{M}$, GGTI298 $5 \mu \mathrm{M}$, FTI277 $5 \mu \mathrm{M}$, and YM53601 $5 \mu \mathrm{M}$. (D, E, I and J) Cell proliferation was determined with CCK-8 assays of HCT 116 and SW 480 cells treated with the indicated agents for $48 \mathrm{~h}$ in $10 \% \mathrm{FBS}$. The concentrations of the agents were as follows: Gefitinib (HCT 116) $6 \mu \mathrm{M}$ or (SW 480) $12 \mu \mathrm{M}$, simvastatin $1 \mu \mathrm{M}$, GGPP $10 \mu \mathrm{M}$, squalene $10 \mu \mathrm{M}$, GGTI298 $5 \mu \mathrm{M}$, FTI277 $5 \mu \mathrm{M}$, and YM53601 $5 \mu \mathrm{M}$. (F and K) Cells were lysed and analyzed by immunoblotting as indicated. HCT 116 and SW 480 were treated with the indicated agents for $48 \mathrm{~h}$. The concentrations of the agents were as follows: Simvastatin $10 \mu \mathrm{M}$, cetuximab $0.7 \mu \mathrm{M}$, gefitinib (HCT 116) $6 \mu \mathrm{M}$ or (SW 480) $12 \mu \mathrm{M}$, GGPP $10 \mu \mathrm{M}$. DMSO served as the control. All the data are displayed as the means \pm SEM; $\mathrm{n}=3$ biological replicates. The two-tailed Student's t-test was used. ${ }^{* *} \mathrm{P}<0.01$. Cet, cetuximab; Gef, gefitinib; Sim, simvastatin; Squ, squalene; DMSO, dimethyl sulfoxide.

the cell proliferation inhibition mediated by simvastatin and EGFR inhibitors (Fig. 7B, D, G and I), while a combination of GGTI298 and cetuximab (or gefitinib), achieved approximately the same effect as the combination of simvastatin and cetuximab (or gefitinib) (Fig. 7C, E, H and J). In addition, after adding back GGPP, the expression of YAP exhibited no obvious change, but the expression of CYR61 was markedly increased, which indicated that YAP bioactivity was recovered (Fig. 7F and K, lanes 4 and 8), consistent with this, the inhibition of cyclin D1 and cell proliferation caused by the combination of simvastatin and EGFR inhibitors was rescued (Fig. 7F and $\mathrm{K}$, lanes 5 and 9; lanes 6 and 10; Fig. 7B and D; G and I). Collectively, the aforementioned data indicated that the simvastatin-induced inhibition with EGFR inhibitors was mainly mediated through the GGPP pathway but not through the farnesyl pyrophosphate (FPP) pathway or squalene pathway (Fig. 7A).

\section{Discussion}

Resistance to EGFR inhibitors, such as cetuximab and gefitinib, has become an urgent issue for both basic science and clinical investigators (15-17). Driver genes, such as mutant KRAS, BRAF, PTEN and PIK3CA, are closely related to this resistance. In the present study, we observed that YAP may be useful in identifying cetuximab resistance in CRC cells. At present, the reported YAP inhibitors include verteporfin (18), statins and zoledronic acid $(9,10)$. In the present study, we primarily used simvastatin as a YAP inhibitor. Simvastatin could not only inhibit total YAP protein expression but it also inhibited YAP translocation into the nucleus. However, simvastatin did not inhibit YAP mRNA levels, indicating that simvastatin promoted YAP protein degradation at the post-transcriptional level. Several studies have demonstrated 


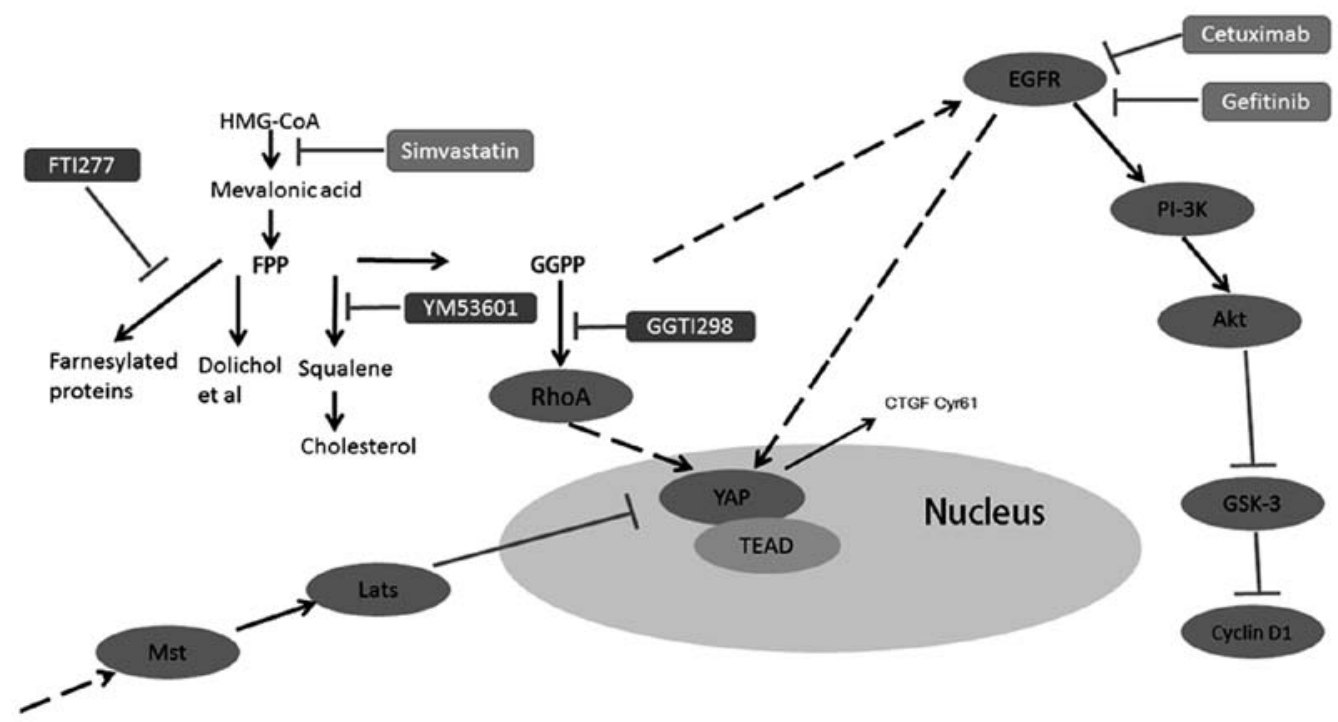

Figure 8. The enhancement mechanism of simvastatin and EGFR inhibitors in CRC cancer cells. The enhancement mechanism of simvastatin and EGFR inhibitors: i) YAP bioactivity is mainly controlled by three signals: RHOA, EGFR and LATS; ii) EGFR pathway signaling promotes the expression of YAP and its downstream targets; iii) simvastatin inhibits YAP bioactivity through RHOA and EGFR; iv) simvastatin inhibits the expression of AKT through EGFR; v) combined use of simvastatin and EGFR inhibitors can inhibit YAP and EGFR signaling more thoroughly than a single agent and achieve synthetic lethality. CRC, colorectal cancer; YAP, yes-associated protein.

that statins mainly inhibit YAP nuclear translocation to decrease its bioactivity, while the total YAP protein expression is not affected $(9,19)$. We thought this discrepancy may be due to differences in the cell types used in each study.

The in vitro and in vivo study results demonstrated that the combination of simvastatin and EGFR inhibitors caused synthetic inhibition of cell proliferation. These results were consistent to the findings of Lee et al but did not reveal the function of YAP in cetuximab resistance (20). Compared with the cetuximab group, cetuximab + simvastatin markedly decreased the nuclear YAP levels in vivo. Furthermore, both pEGFR and pAKT were inhibited more markedly with the combination treatment than with single agents in vitro and in vivo. The aforementioned results were consistent with the cell proliferation and xenograft tumor growth assay results (Figs. 4 and 5).

Simvastatin induced pAKT downregulation in the present study. We hypothesized that this decrease may be caused by EGFR and (or) PTEN. In addition, our investigation revealed that simvastatin inhibited pEGFR but not PTEN, which indicated that simvastatin-induced AKT signaling was downregulated through EGFR. While EGF caused pEGFR and pAKT upregulation, this could be reversed by simvastatin, which verified this hypothesis. Furthermore, addition of GGPP reversed simvastatin-induced EGFR-AKT signal downregulation, revealing that simvastatin-mediated inhibition of EGFR-AKT signaling may occur through GGPP.

Crosstalk between the Hippo signaling and other pathway signals is involved in tumorigenesis, cancer progression and drug resistance (21-24). In the present study, YAP knockdown had nearly no effect on EGFR signaling, while EGF treatment promoted the activation of YAP and CYR61. These results could partly explain some epidemiological studies, which reported that no benefit was observed in simvastatin users for cancer therapy $(25,26)$, and the reason may be inadequate inhibition of YAP. In addition to EGFR signaling, YAP is also regulated by other signals, such as RHOA, LATS and $\mathrm{G}$ protein-coupled receptors $(10,27)$. Therefore, it is difficult to fully inhibit YAP bioactivity, and multiple inhibition approaches may be an effective and feasible method, as demonstrated in our study (Fig. 6F, lanes 5,6 and 8).

Recent studies have revealed that the antitumor effects of simvastatin are controversial $(25,26,28-30)$. As an HMG-CoA reductase inhibitor, simvastatin can inhibit the mevalonate pathway specifically. The mevalonate pathway is involved in biosynthesis of squalene, GGPP and farnesyl pyrophosphate (FPP) (31). Squalene is an upstream product of cholesterol synthesis, and GGPP and FPP are critical for prenylation of small $\mathrm{G}$ proteins, such as those in the RAS, RHO and RAB families (Fig. 7A). In the present study, GGPP rescued CYR61 expression inhibited by simvastatin, but did not markedly alter YAP expression. The immunofluorescence analysis results revealed that GGPP partly reversed the effects of simvastatin on nuclear YAP levels. This may be because GGPP rescued YAP bioactivity primarily through YAP protein transportation to the nucleus and not by increasing YAP protein expression. Consistent with this, GGPP reversed the synthetic cell proliferation inhibition caused by simvastatin and the EGFR inhibitors. All of the aforementioned results revealed the effect of YAP bioactivity on the resistance to EGFR inhibitors. This was in accordance with the study of Lee $e t a l$, in which a significant association between the oncogene YAP1 and cetuximab resistance was reported (8). However, their analysis was mainly focused on clinical patients. In addition, combined treatment with GGTI298 and EGFR inhibitors caused proliferation inhibition similar to that of the combination of EGFR inhibitors and simvastatin. However, combing FTI277 (or YM53601) and EGFR inhibitors had little effect compared with EGFR inhibitors alone. These results demonstrated that the GGPP pathway mainly mediated the combined effect of simvastatin and EGFR inhibitors (Fig. 8). 
Notably, the concentration of simvastatin used in vitro was much higher ( $>10$-fold) than that typically used for lowering cholesterol, a dosage of approximately $0.2-1.5 \mathrm{mg} / \mathrm{kg} /$ day and thus, toxic effects at such concentrations should be evaluated clinically.

In the present study, we found that YAP knockdown enhanced the sensitivity of CRC cells to cetuximab, and inhibition of YAP bioactivity by simvastatin increased the cytotoxicity of cetuximab and gefitinib. The combination of simvastatin and EGFR inhibitors synthetically inhibited YAP and EGFR signals. Our findings revealed a new promising therapeutic strategy to enhance the efficacy of CRC treatment through combined YAP and EGFR targeting (Fig. 8) and indicated that further studies of YAP inhibitors and the effects of YAP on cetuximab resistance should be performed.

\section{Acknowledgements}

Not applicable.

\section{Funding}

The present study was supported by the National Key R\&D Program of China (grant no. 2016YFC1303200/ 2016YFC1303203), the National Natural Science Foundation of China (grant no. 81621003) and the National Natural Science Foundation for Young Scholars of China (grant no. 81502655).

\section{Availability of data and materials}

The datasets used during the present study are available from the corresponding author upon reasonable request.

\section{Authors' contributions}

BSL and HWX designed and performed the experiments, analyzed the data and prepared the manuscript. SZ, QL and NXB contributed to studies related to Hoechst 33342 staining, real-time PCR and in vivo experiments. QLT and JTZ conducted immunoblotting to examine the EGFR pathway and colony formation assays. QYG and YZN analyzed the data and contributed to the manuscript. FB supervised and designed the experiments, analyzed the data and prepared the manuscript. All authors read and approved the manuscript and agree to be accountable for all aspects of the research in ensuring that the accuracy or integrity of any part of the work are appropriately investigated and resolved.

\section{Ethics approval and consent to participate}

All animal experimental procedures used in the present study were approved by the Experimental Animal Manage Committee of West China Hospital, Sichuan University under contract 2016003A and were performed strictly according to the guidelines of the Animal Ethics Committee Guidelines of the Animal Facility of West China Hospital and the Animal Care and Use Committee of Sichuan University (Chengdu, China).

\section{Patient consent for publication}

Not applicable.

\section{Competing interests}

The authors declare that they have no competing interests.

\section{Authors' information}

NXB is a volunteer student from Chengdu International School (Chengdu, Sichuan).

\section{References}

1. Siegel R, Naishadham D and Jemal A: Cancer statistics, 2012. CA Cancer J Clin 62: 10-29, 2012.

2. Ferlay J, Shin HR, Bray F, Forman D, Mathers C and Parkin DM: Estimates of worldwide burden of cancer in 2008: GLOBOCAN 2008. Int J Cancer 127: 2893-2917, 2010.

3. Goldberg RM, Sargent DJ, Morton RF, Fuchs CS, Ramanathan RK, Williamson SK, Findlay BP, Pitot HC and Alberts SR: A randomized controlled trial of fluorouracil plus leucovorin, irinotecan, and oxaliplatin combinations in patients with previously untreated metastatic colorectal cancer. J Clin Oncol 22: 23-30, 2004.

4. Heinemann V, von Weikersthal LF, Decker T, Kiani A, Vehling-Kaiser U, Al-Batran SE, Heintges T, Lerchenmuller C, Kahl C, Seipelt G, et al: FOLFIRI plus cetuximab versus FOLFIRI plus bevacizumab as first-line treatment for patients with metastatic colorectal cancer (FIRE-3): A randomised, open-label, phase 3 trial. Lancet Oncol 15: 1065-1075, 2014.

5. Stintzing S, Modest DP, Rossius L, Lerch MM, von Weikersthal LF, Decker T, Kiani A, Vehling-Kaiser U, Al-Batran SE, Heintges T, et al: FOLFIRI plus cetuximab versus FOLFIRI plus bevacizumab for metastatic colorectal cancer (FIRE-3): A post-hoc analysis of tumour dynamics in the final RAS wild-type subgroup of this randomised open-label phase 3 trial. Lancet Oncol 17: 1426-1434, 2016.

6. Camargo FD, Gokhale S, Johnnidis JB, Fu D, Bell GW, Jaenisch R and Brummelkamp TR: YAP1 increases organ size and expands undifferentiated progenitor cells. Curr Biol 17: 2054-2060, 2007.

7. Yu FX, Meng Z, Plouffe SW and Guan KL: Hippo pathway regulation of gastrointestinal tissues. Annu Rev Physiol 77: 201-227, 2015.

8. Lee KW, Lee SS, Kim SB, Sohn BH, Lee HS, Jang HJ, Park YY, Kopetz S, Kim SS, Oh SC, et al: Significant association of oncogene YAP1 with poor prognosis and cetuximab resistance in colorectal cancer patients. Clin Cancer Res 21: 357-364, 2015.

9. Wang Z, Wu Y, Wang H, Zhang Y, Mei L, Fang X, Zhang X, Zhang F, Chen H, Liu Y, et al: Interplay of mevalonate and hippo pathways regulates RHAMM transcription via YAP to modulate breast cancer cell motility. Proc Natl Acad Sci USA 111: E89-E98, 2014.

10. Sorrentino G, Ruggeri N, Specchia V, Cordenonsi M, Mano M, Dupont S, Manfrin A, Ingallina E, Sommaggio R, Piazza S, et al: Metabolic control of YAP and TAZ by the mevalonate pathway. Nat Cell Biol 16: 357-366, 2014.

11. Livak KJ and Schmittgen TD: Analysis of relative gene expression data using real-time quantitative PCR and the $2^{-\Delta \Delta C_{\mathrm{T}}}$ method. Methods 25: 402-408, 2001.

12. Ma J, Xue Y, Liu W, Yue C, Bi F, Xu J, Zhang J, Li Y, Zhong C and Chen Y: Role of activated Rac1/Cdc42 in mediating endothelial cell proliferation and tumor angiogenesis in breast cancer. PLoS One 8: e66275, 2013.

13. Van Cutsem E, Kohne CH, Hitre E, Zaluski J, Chang Chien CR, Makhson A, D'Haens G, Pinter T, Lim R, Bodoky G, et al: Cetuximab and chemotherapy as initial treatment for metastatic colorectal cancer. N Engl J Med 360: 1408-1417, 2009.

14. Mullen PJ, Yu R, Longo J, Archer MC and Penn LZ: The interplay between cell signalling and the mevalonate pathway in cancer. Nat Rev Cancer 16: 718-731, 2016.

15. Yen LC, Uen YH, Wu DC, Lu CY, Yu FJ, Wu IC, Lin SR and Wang JY: Activating KRAS mutations and overexpression of epidermal growth factor receptor as independent predictors in metastatic colorectal cancer patients treated with cetuximab. Ann Surg 251: 254-260, 2010. 
16. De Roock W, Claes B, Bernasconi D, De Schutter J, Biesmans B, Fountzilas G, Kalogeras KT, Kotoula V, Papamichael D, Laurent-Puig P, et al: Effects of KRAS, BRAF, NRAS, and $P I K 3 C A$ mutations on the efficacy of cetuximab plus chemotherapy in chemotherapy-refractory metastatic colorectal cancer: A retrospective consortium analysis. Lancet Oncol 11: 753-762, 2010.

17. Chiu CF, Chang YW, Kuo KT, Shen YS, Liu CY, Yu YH, Cheng CC, Lee KY, Chen FC, Hsu MK, et al: NF- $\kappa \mathrm{B}$-driven suppression of FOXO3a contributes to EGFR mutation-independent gefitinib resistance. Proc Natl Acad Sci USA 113: E2526-E2535, 2016

18. Yu FX, Luo J, Mo JS, Liu G, Kim YC, Meng Z, Zhao L, Peyman G, Ouyang $\mathrm{H}$, Jiang $\mathrm{W}$, et al: Mutant $\mathrm{Gq} / 11$ promote uveal melanoma tumorigenesis by activating YAP. Cancer Cell 25: 822-830, 2014

19. Wang KC, Yeh YT, Nguyen P, Limqueco E, Lopez J, Thorossian S, Guan KL, Li YJ and Chien S: Flow-dependent YAP/TAZ activities regulate endothelial phenotypes and atherosclerosis. Proc Natl Acad Sci USA 113: 11525-11530, 2016.

20. Lee J, Lee I, Han B, Park JO, Jang J, Park C and Kang WK: Effect of simvastatin on cetuximab resistance in human colorectal cancer with KRAS mutations. J Natl Cancer Inst 103: 674-688, 2011.

21. Hong X, Nguyen HT, Chen Q, Zhang R, Hagman Z, Voorhoeve PM and Cohen SM: Opposing activities of the Ras and Hippo pathways converge on regulation of YAP protein turnover. EMBO J 33: 2447-2457, 2014

22. Song S, Honjo S, Jin J, Chang SS, Scott AW, Chen Q, Kalhor N, Correa AM, Hofstetter WL, Albarracin CT, et al: The hippo coactivator YAP1 mediates EGFR overexpression and confers chemoresistance in esophageal cancer. Clin Cancer Res 21: 2580-2590, 2015.

23. He C, Lv X, Hua G, Lele SM, Remmenga S, Dong J, Davis JS and Wang C: YAP forms autocrine loops with the ERBB pathway to regulate ovarian cancer initiation and progression. Oncogene 34 6040-6054, 2015.
24. He C, Mao D, Hua G, Lv X, Chen X, Angeletti PC, Dong J, Remmenga SW, Rodabaugh KJ, Zhou J, et al: The Hippo/YAP pathway interacts with EGFR signaling and HPV oncoproteins to regulate cervical cancer progression. EMBO Mol Med 7: 1426-1449, 2015

25. Pocobelli G, Newcomb PA, Trentham-Dietz A, Titus-Ernstoff L, Hampton JM and Egan KM: Statin use and risk of breast cancer. Cancer 112: 27-33, 2008.

26. Freeman SR, Drake AL, Heilig LF, Graber M, McNealy K, Schilling LM and Dellavalle RP: Statins, fibrates, and melanoma risk: A systematic review and meta-analysis. J Natl Cancer Inst 98: 1538-1546, 2006.

27. Zhang Y, Xia H, Ge X, Chen Q, Yuan D, Chen Q, Leng W, Chen L, Tang Q and Bi F: CD44 acts through RhoA to regulate YAP signaling. Cell Signal 26: 2504-2513, 2014.

28. Farwell WR, Scranton RE, Lawler EV, Lew RA, Brophy MT, Fiore LD and Gaziano JM: The association between statins and cancer incidence in a veterans population. J Natl Cancer Inst 100: 134-139, 2008.

29. Cauley JA, McTiernan A, Rodabough RJ, LaCroix A Bauer DC, Margolis KL, Paskett ED, Vitolins MZ, Furberg CD and Chlebowski RT; Women's Health Initiative Research Group: Statin use and breast cancer: Prospective results from the Women's Health Initiative. J Natl Cancer Inst 98: 700-707, 2006.

30. Lee J, Hong YS, Hong JY, Han SW, Kim TW, Kang HJ, Kim TY, Kim KP, Kim SH, Do IG, et al: Effect of simvastatin plus cetuximab/irinotecan for KRAS mutant colorectal cancer and predictive value of the $R A S$ signature for treatment response to cetuximab. Invest New Drugs 32: 535-541, 2014.

31. Goldstein JL and Brown MS: Regulation of the mevalonate pathway. Nature 343: 425-430, 1990 . 